\title{
Morphometric and Topographic Study of Foramen Ovale in Indian Skulls
}

\author{
Suniti Raj Mishra ${ }^{1 *}$, Sushobhana ${ }^{2}$, Shailendra Singh ${ }^{3}$, Raveena Singh $^{4}$, Anamika Gaharwar \\ ${ }^{1}$ Professor and Head, Department of Anatomy, G.S.V.M. Medical College, Kanpur, INDIA \\ ${ }^{2,4}$ Postgraduate Student, Department of Anatomy, G.S.V.M. Medical College, Kanpur, INDIA \\ ${ }^{3}$ Lecturer, Department of Anatomy, G.S.V.M. Medical College, Kanpur, INDIA \\ ${ }^{5}$ Assistant Professor, Department of Anatomy, G.S.V.M. Medical College, Kanpur, INDIA \\ *Email for Correspondence: dr.suniti@yahoo.co.in
}

\begin{abstract}
Foramen ovale is an important foramen for neurosurgeons and used for percutaneous trigeminal rhizotomy in trigeminal neuralgia. The present study was undertaken to study anatomic variations in appearance, dimensions of foramen ovale and its location in relation to the zygomatic arch.

The study was conducted on 50 dry human skulls of known sex, available in the museum of Anatomy Dept. in G.S.V.M. Medical College, Kanpur. The shape of foramen ovale and presence of any accessory bony structure like spur, spine, tubercle or bony plate were observed on both sides. The length and width of foramen ovale and its distance from articular tubercle and the anterior root of Zygomatic Arch was measured on both sides. The metric data was statistically analysed for bilateral symmetry and sexual dimorphism.

The shape of foramen ovale was typically oval in most of the skulls (66\%). In $40 \%$ sides any accessory bony structure was not seen while bony plate in $45 \%$ sides, spine in $6 \%$ and bridge like bony septa dividing the foramen into two compartments in $2 \%$ was observed. The mean length and width of foramen ovale in male skulls was $7.50+/-0.90 \mathrm{~mm}$ and $4.20+/-0.70 \mathrm{~mm}$ and $7.7+/-1.00 \mathrm{~mm}$ and $3.9+/-0.80$ $\mathrm{mm}$ in the female skulls. The mean distance of foramen ovale from articular tubercle on Zygomatic arch was $32.8+/-2.8 \mathrm{~mm}$ in males and $31.1+/-2.4 \mathrm{~mm}$ in females. The mean distance from anterior root of Zygomatic arch was $21.4+/-1.9 \mathrm{~mm}$ in males and $21.6+/-1.7 \mathrm{~mm}$ in females.

There was no significant difference in measurements of various metric parameters between right and left sides of foramen ovale $(\mathrm{p}>0.05)$ but highly significant difference was observed between male and female dimensions of all metric parameters. $(\mathrm{p}<0.001)$. Thus the foramen ovale does not exhibit bilateral symmetry but the sexual dimorphism is evident. The data is helpful for surgical practices.
\end{abstract}

Key words: Base of Skull, Emissary Vein, Foramen Spinosum, Mandibular Nerve, Middle Cranial Fossa, Sphenoid, Trigeminal Neuralgia, Zygomatic Arch

\begin{tabular}{ll}
\hline 7/24/2016 & Source of Support: None, No Conflict of Interest: Declared \\
\hline $\begin{array}{l}\text { This article is is licensed under a Creative Commons Attribution-NonCommercial 4.0 International License. } \\
\text { Attribution-NonCommercial (CC BY-NC) license lets others remix, tweak, and build upon work non-commercially, and although the new works must also } \\
\text { acknowledge \& be non-commercial. }\end{array}$ CC) 8 BY
\end{tabular}

\section{INTRODUCTION}

The foramina of the skull, their size, shape, symmetry, variations and location have long attracted the attention of anatomists, anthropologists, forensic experts and clinicians because of their clinical, radiographic and evolutionary significance. The foramen ovale is an important foramen present in the middle cranial fossa, at the posterior part of the greater wing of the sphenoid bone. It is located posterolateral to the foramen rotundum, anteromedial to the foramen spinosum and anterior to Foramen lacerum connecting the middle cranial fossa with the infratemporal fossa. The mandibular nerve, accessory meningeal artery, the lesser petrosal nerve and emissary vein pass through it. The longitudinal axis of foramen is oriented slightly ventrally and laterally, corresponding to the direction of the mandibular nerve ( Lawrence et al .,1994). 
It's noteworthy that the foramen ovale is not present in the class reptilia and was acquired in mammal during the process of evolution (Edinger and Kitts, 1954). The foramen is absent in some living mammals including the mammalian embryo, where the semilunar ganglion develops outside the skull and its intracranial position is secondary in ontogeny. So a theory was concluded that a separate exit of mandibular nerve through foramen ovale is an advanced character acquired during the evolution of some orders (Edinger and Kitts, 1954). Thus morphometry of foramen ovale provides an insight into the evolutionary history of human.

The foramen ovale (FO) is of great surgical and diagnostic importance in procedures like fine needle aspiration via transfacial approach, in the perineural spread of tumour, trigeminal rhizotomy via percutaneous approach for trigeminal neuralgia and the electroencephalographic analysis. However, variations are seen in the shape and size of the FO which bear important clinical implications. Thus the present study was carried out to identify the metric and non metric morphometry of foramen ovale and its topographic location in relation to zygomatic arch.

\section{Materials AND Methods}

The present study was undertaken on 50 dry, adult human skulls (27males \& 23 Females) obtained from Anthropology museum of Anatomy department, G.S.V.M. Medical College, Kanpur. The observations were measured on both Right \& Left sides in each skull. Thus 100 foramen ovale in 50 skulls were studied. The sex of the skull was taken in account. The Non-Metric parameter studied were a)-Shape of the foramen ovale b)- Presence of any accessory bony structure like bony plate, spine, tubercle, septa ,if any.

The metric parameter studied were a).Length of foramen ovale (mediolateral) and b) Width of foramen ovale (anteroposterior). The two dimensions of the foramen ovale measured were along its long and short axes respectively, measured with a vernier calliper of $0.1 \mathrm{~cm}$ precision. c) Distance from the anterior root of zygoma d) Distance from the articular tubercle on zygomatic arch.

The data so obtained was statistically analysed for the morphometry as well as sexual dimorphism.

\section{RESULTS}

The Foramen ovale was present bilaterally in all skulls. In the study the shape of the foramen ovale was oval in $66 \%$ cases while almond shaped in $22 \%$ cases, longitudinal (slit-like) in $4 \%$ cases, round in 3\%, D shaped in $2 \%$ and irregular in $3 \%$ cases. (Table 1; figure 1-5). Out of 50 skull the bilateral symmetric shape was seen in 30 skulls $(60 \%)$ but the asymmetry in size i.e dimensions in terms of length and width were bilaterally different in $100 \%$ of skulls.

The 3\% irregular foramen included one foramen showing confluence of the foramen ovale with the foramen spinosum unilaterally on the left side. One skull showed confluence of the foramen ovale with the foramen spinosum and foramen lacerum bilaterally.

Table 1: Showing variation in shape of foramen ovale in both sexes on both sides

\begin{tabular}{|l|l|l|l|l|l|l|}
\hline S.N & Shape & Male $(\mathrm{n}=54)$ & \multicolumn{2}{l|}{ Female $(\mathrm{n}=46)$} & Total $\mathrm{n}=100(\%)$ \\
\hline & & Right & Left & Right & Left & \\
\hline 1 & Oval & 14 & 20 & 16 & 16 & 66 \\
\hline 2 & Almond & 10 & 5 & 3 & 4 & 22 \\
\hline 3 & D shaped / & 0 & 1 & 0 & 1 & 2 \\
\hline 4 & Longitudinal (Slit Like) & 0 & 0 & 2 & 2 & 4 \\
\hline 5 & Round & 1 & 1 & 1 & 0 & 3 \\
\hline 6 & Irregular(Primitive) & 0 & 1 & 1 & 1 & 3 \\
\hline
\end{tabular}

Figure 1: Oval shape of Foramen Ovale on Left side and almond shaped on right side

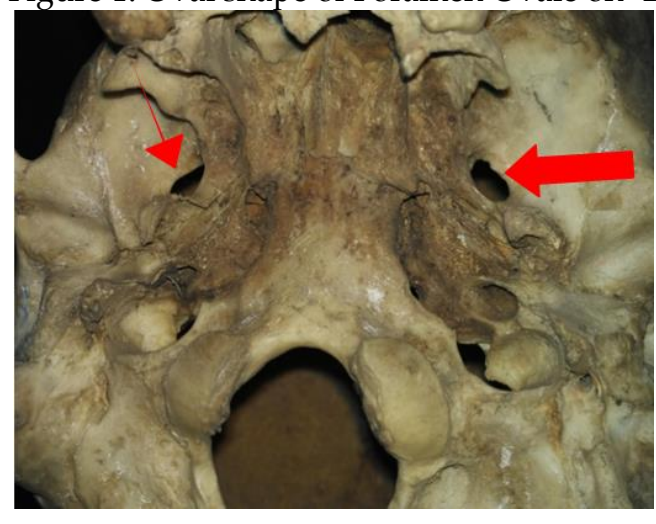


Figure 2: D shape of Foramen Ovale

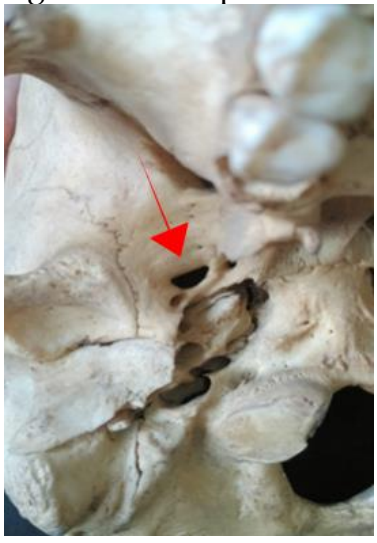

Figure 3: Round shape of Foramen Ovale

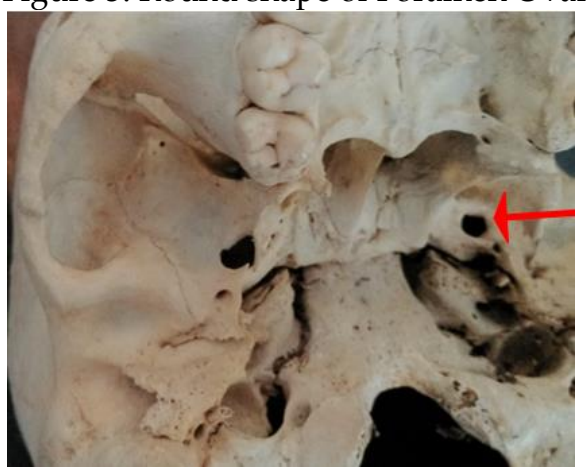

Figure 4: Longitudinal shape of Foramen Oval

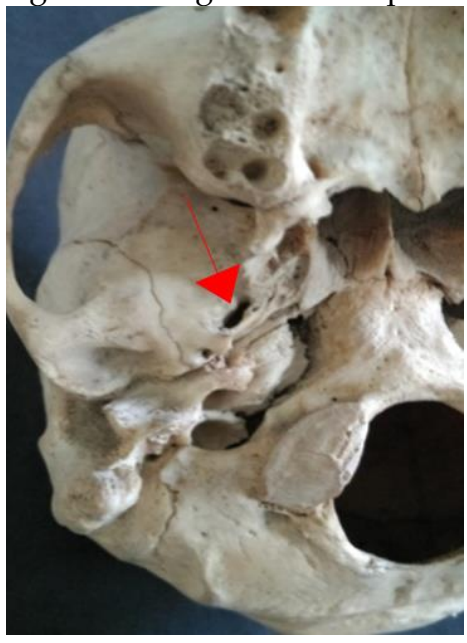

Figure 5: Irregular shape of Foramen Ovale (Primitive ) showing A. Persistent foramen lacerum medius on right side and B. confluence of foramen ovale and foramen spinosum on left side. C. Partial confluence of foramen ovale and foramen spinosum
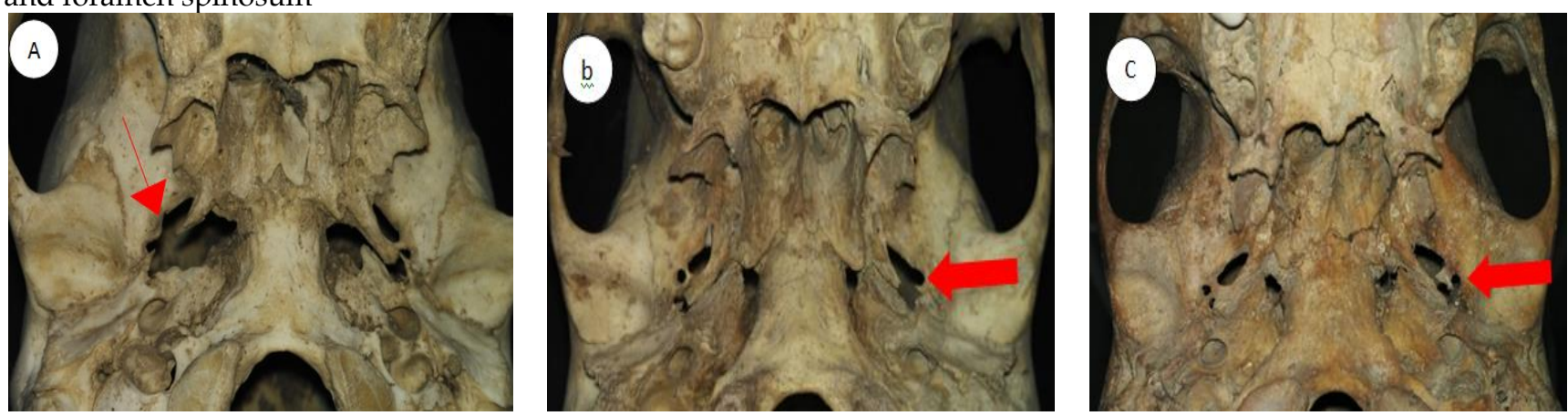
The outline of foramen was not smooth and regular in all cases and there was an accessory bony structure present in some of them. A bony plate was present in $38 \%$ cases, spine in $7 \%$ cases, septa in $2 \%$, tubercle in $5 \%$. However no bony accessory structure was seen in $47 \%$ cases. In 3\% cases the foramen was incomplete and irregular. (Table 2 ; Figure- 6-10). Asymmetry between the right and the left side was present.

A thin bony septa at right angles to the long axis (i.e. medio-lateral) of the foramen was observed in 2 foramen dividing the foramen into two compartments of approximately equal size (Fig. 9).

Table 2: Showing incidence of accessory bony structure in foramen ovale in both sexes on both sides

\begin{tabular}{|l|l|l|l|l|l|l|}
\hline S.N & Parameter & \multicolumn{2}{l|}{ Male $(\mathrm{n}=54)$} & \multicolumn{2}{l|}{ Female $(\mathrm{n}=46)$} & Total F.O. $\mathrm{n}=100$ \\
\hline & Accessory bony structure & Right & \multicolumn{1}{l|}{ Left } & Right & Left & \\
\hline 1 & No asso. bony structure & 12 & 14 & 10 & 11 & $47 \%$ \\
\hline 2 & Bony plate & 10 & 11 & 8 & 9 & $38 \%$ \\
\hline 3 & Spine & 2 & 2 & 3 & 0 & $7 \%$ \\
\hline 4 & Septa & 2 & 0 & 0 & 0 & $2 \%$ \\
\hline 5 & Tubercle & 1 & 0 & 1 & 3 & $5 \%$ \\
\hline 6 & Incomplete & 0 & 1 & 1 & 1 & $3 \%$ \\
\hline
\end{tabular}

Figure 6: Showing accessory bony structure (A\&B): Bony plate
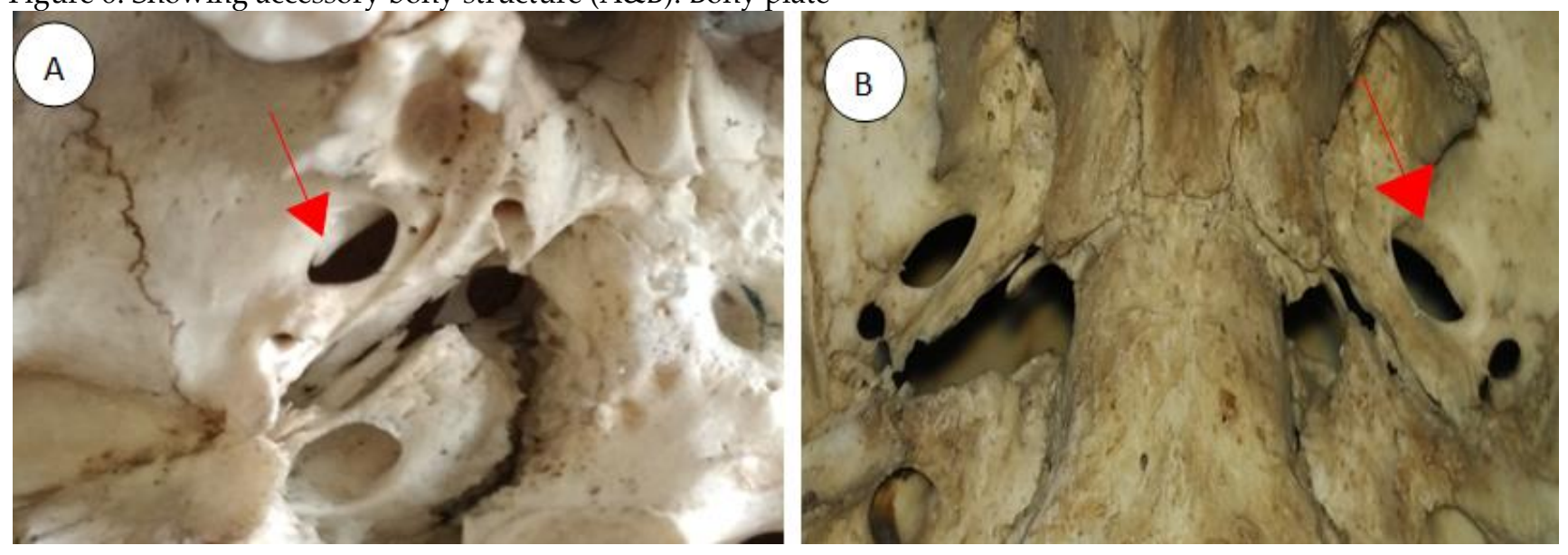

Figure 7: Showing accessory bony structure (A\&B): Spine

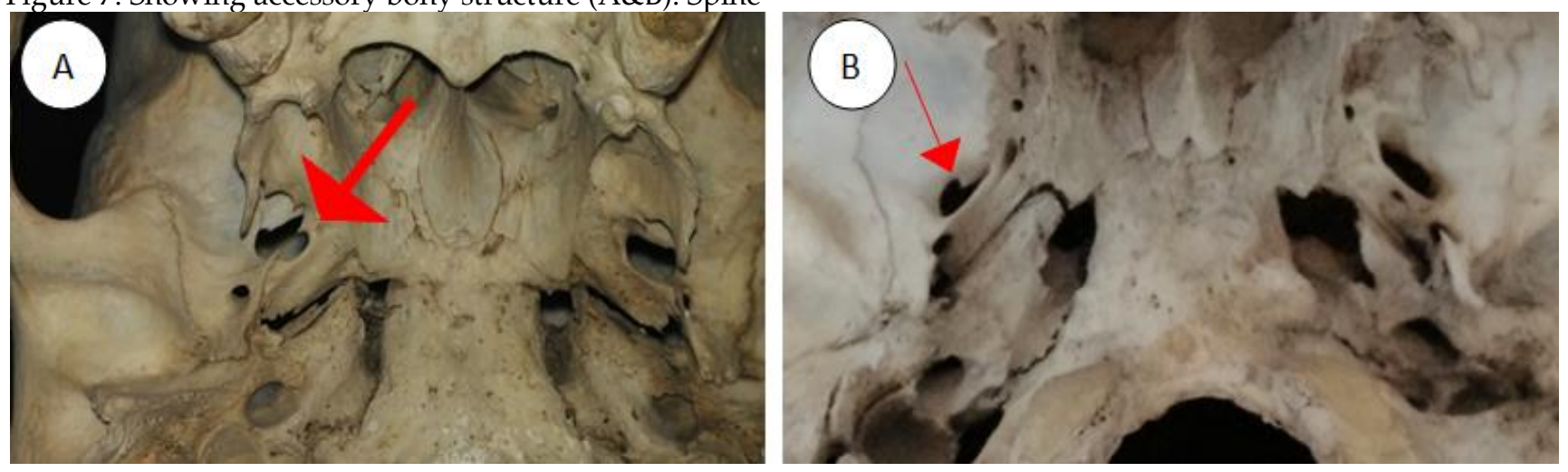

Figure 8: Showing accessory bony structure (A\&B): Tubercle

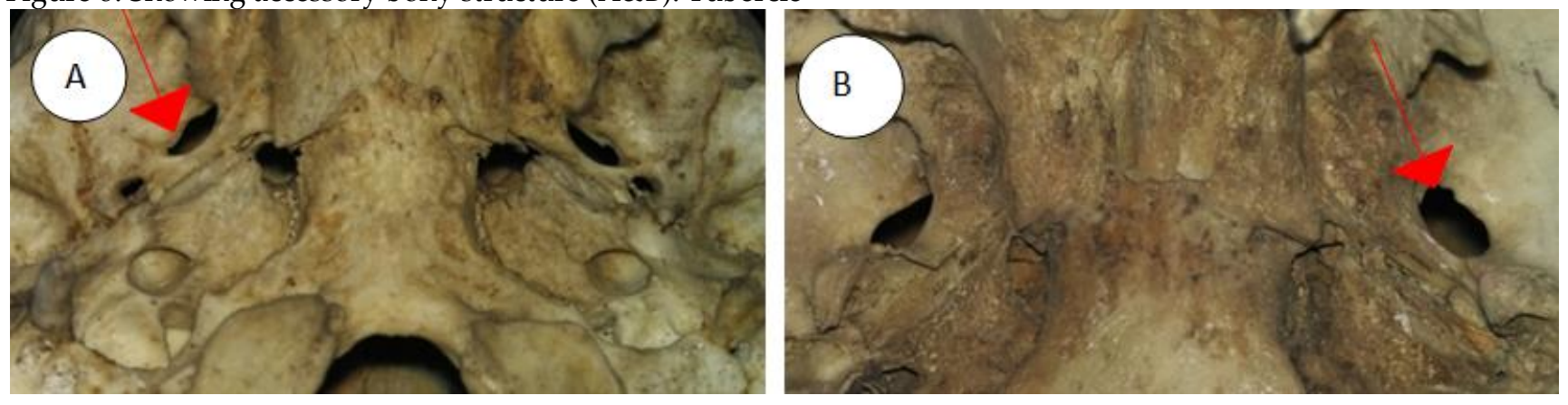


Figure 9: Showing accessory bony structure: Septa

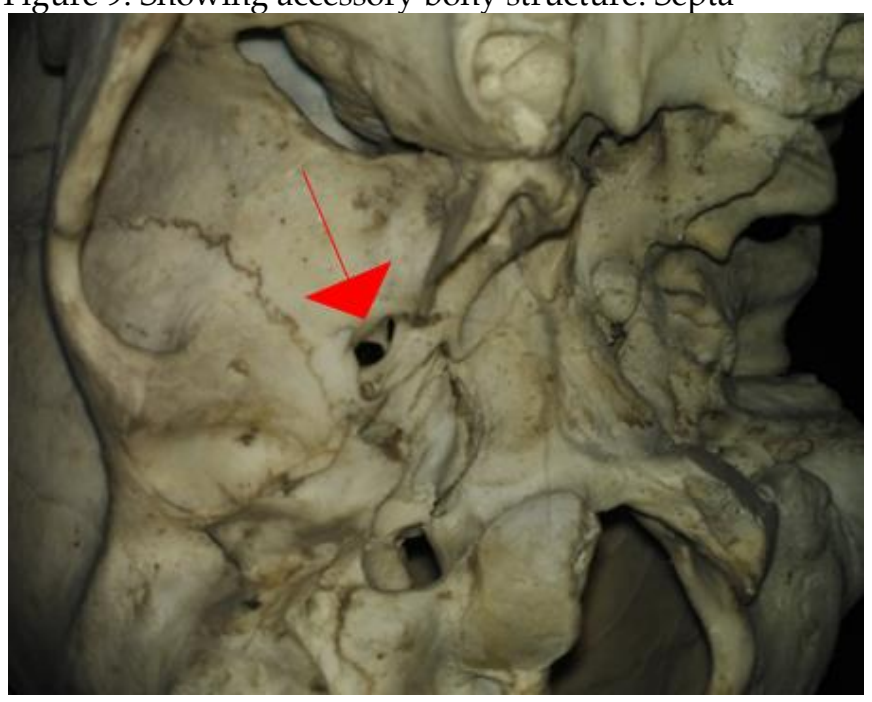

The range of length of foramen ovale in males was 5.4- $10.2 \mathrm{~mm}$ while it was $5.4-11.1 \mathrm{~mm}$ in females. The overall range of length of foramen ovale irrespective of sex was 5.4- $11.1 \mathrm{~mm}$ and the range of width was 1.7- 8.2 mm.

The mean length and width of foramen ovale in male skulls was $7.50+/-0.90 \mathrm{~mm}$ and $4.20+/-0.70 \mathrm{~mm}$ and $7.7+/-1.00$ $\mathrm{mm}$ and $3.9+/-0.80 \mathrm{~mm}$ in the female skulls. There was no significant difference between right and left sides in both sexes. However the difference between the dimensions was statistically highly significant in the two sexes. (Table 3)

Table 3: Showing dimensions of foramen ovale and the statistical analysis in both sexes

\begin{tabular}{|c|c|c|c|c|c|}
\hline S.N & Parameter & \multicolumn{2}{|l|}{ Male } & \multicolumn{2}{|l|}{ Female } \\
\hline & Dimensions & Right & Left & Right & Left \\
\hline 1 & Length & \multicolumn{4}{|l|}{ (in $\mathrm{mm}$ ) } \\
\hline & Range & $5.4-10.2$ & $5.6-8.9$ & $5.4-10.0$ & $6.0-11.1$ \\
\hline & Mean \pm S.D & $7.6 \pm 1.2$ & $7.5 \pm 1.0$ & $8.0 \pm 1.2$ & $8.0 \pm 1.1$ \\
\hline & T test / P value & \multicolumn{2}{|c|}{$\mathrm{P}>0.05$ (not significant) } & \multicolumn{2}{|c|}{$\mathrm{P}>0.05$ (not significant) } \\
\hline & Mean \pm S.D & \multicolumn{2}{|c|}{$7.5 \pm 0.9$} & \multicolumn{2}{|c|}{$7.7 \pm 1.0$} \\
\hline & T test / P value (Male \& Female) & \multicolumn{4}{|c|}{$P>0.001$ Highly Significant } \\
\hline 2 & Width & \multicolumn{4}{|l|}{ (in $\mathrm{mm}$ ) } \\
\hline & Range & $3.3-8.2$ & $2.4-5.4$ & $2.0-0.5 .9$ & $1.7-5.3$ \\
\hline & Mean \pm S.D & $4.4 \pm 1.0$ & $4.1 \pm 1.0$ & $4.0 \pm 1.0$ & $4.0 \pm 1.0$ \\
\hline & $\mathrm{T}$ test / $\mathrm{P}$ value & \multicolumn{2}{|c|}{$P>0.05$ (not significant) } & \multicolumn{2}{|c|}{$\mathrm{P}>0.05$ (not significant) } \\
\hline & Mean \pm S.D & \multicolumn{2}{|c|}{$4.2 \pm 0.7$} & \multicolumn{2}{|c|}{$3.9 \pm 0.8$} \\
\hline & $\mathrm{T}$ test / P value (Male \& Female) & \multicolumn{4}{|c|}{$P>0.001$ Highly Significant } \\
\hline
\end{tabular}

The mean distance of foramen ovale from articular tubercle on Zygomatic arch was $32.8+/-2.8 \mathrm{~mm}$ in males and $31.1+/-2.4 \mathrm{~mm}$ in females. The mean distance from anterior root of Zygomatic arch was $21.4+/-1.9 \mathrm{~mm}$ in males and $21.6+/-1.7 \mathrm{~mm}$ in females. (Table 4 figure 10 )

Table 4: Showing distance of foramen ovale from landmarks on zygomatic process and the statistical analysis in both sexes

\begin{tabular}{|c|c|c|c|c|c|}
\hline S.N & Parameter & \multicolumn{2}{|l|}{ Male } & \multicolumn{2}{|l|}{ Female } \\
\hline & & Right & Left & Right & Left \\
\hline \multirow[t]{6}{*}{1} & Distance from root of zygoma & \multicolumn{4}{|l|}{ (in $\mathrm{mm}$ ) } \\
\hline & Range & $13.4-24.3$ & $17.2-27.1$ & $18.2-23.9$ & $12.2-24.2$ \\
\hline & Mean \pm S.D & $21.0 \pm 2.2$ & $22.0 \pm 2.2$ & $21.0 \pm 2.0$ & $21.0 \pm 2.3$ \\
\hline & T test / P value & \multicolumn{2}{|c|}{$\mathrm{P}>0.05$ (not significant) } & \multicolumn{2}{|c|}{$\mathrm{P}>0.05$ (not significant) } \\
\hline & Mean \pm S.D & \multicolumn{2}{|c|}{$21.4 \pm 1.9$} & \multicolumn{2}{|l|}{$20.6 \pm 1.7$} \\
\hline & T test / P value (Male \& Female) & \multicolumn{4}{|c|}{$\mathrm{P}>0.001$ Highly Significant } \\
\hline \multirow[t]{6}{*}{2} & Distance from articular tubercle & \multicolumn{4}{|c|}{ (in $\mathrm{mm}$ ) } \\
\hline & Range & $28.8-37.2$ & $28.7-38.3$ & $27.2-35.2$ & $27.2-35.6$ \\
\hline & Mean \pm S.D & $33.0 \pm 2.2$ & $33.0 \pm 2.3$ & $31.4 \pm 2.5$ & $31.0 \pm 2.5$ \\
\hline & T test / P value & \multicolumn{2}{|c|}{$\mathrm{P}>0.05$ (not significant) } & \multicolumn{2}{|c|}{$\mathrm{P}>0.05$ (not significant) } \\
\hline & Mean \pm S.D & $32.8 \pm 2.8$ & & $31.1 \pm 2.4$ & \\
\hline & T test / P value (Male \& Female & \multicolumn{4}{|c|}{$P>0.001$ Highly Significant } \\
\hline
\end{tabular}


Figure 10: Distance of foramen ovale from A. anterior root of Zygomatic process and B. aricular tubercle
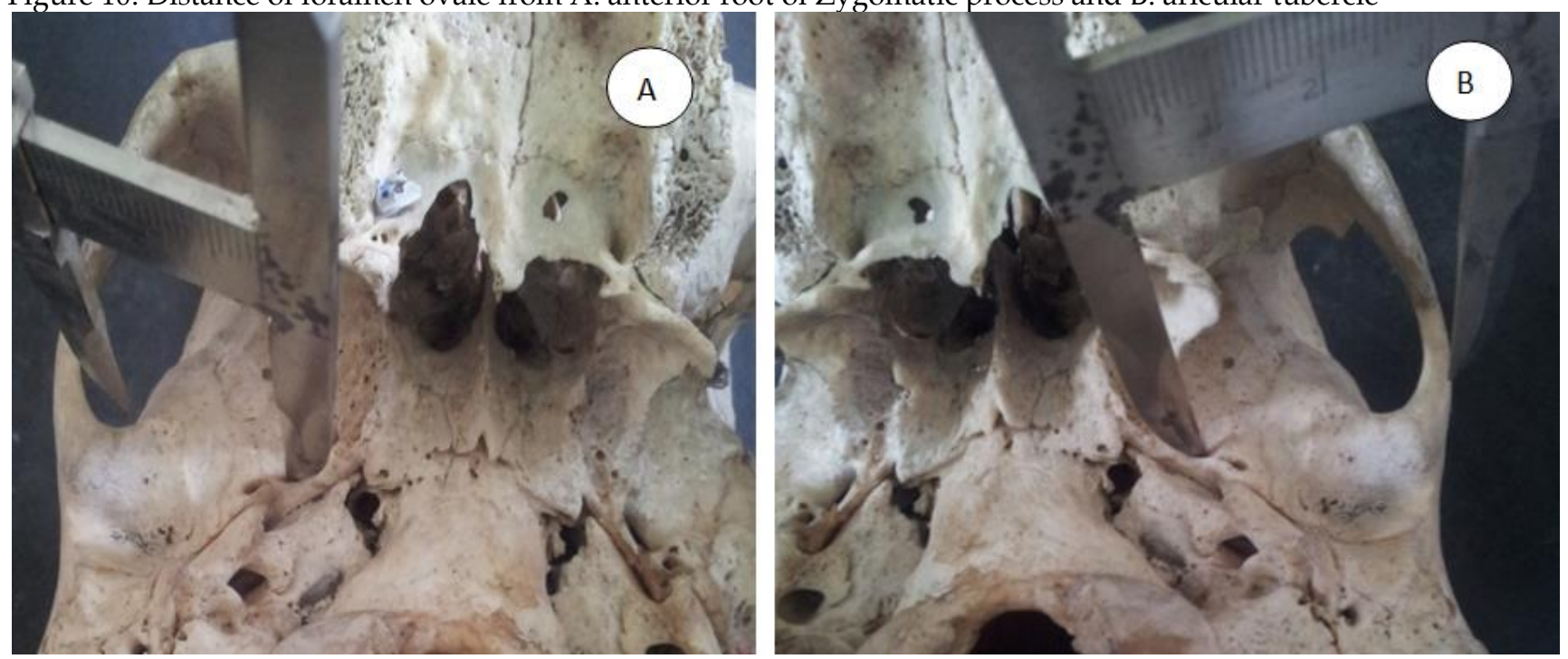

\section{Discussion}

The cranial foramina and the variations in their presence, number, size and location, besides leading to the insight towards evolution, are of high clinical significance due to the neurovascular structures that traverse their narrow confines. Any trauma or space-occupying lesion in this area would result in compressive forces and related clinical manifestations as a consequence (Kato et al., 2006). Therefore, knowledge of the variations in the foramina guides the clinicians towards a correct interpretation of radiographs and also helps in performing surgical procedures in the complicated region. Hauser and De Stefano (1989) further suggested that these cranial variants are the epigenetic factors which occur as a product of the genetically determined growth processes of other tissues such as muscles, vessels and nerves which affect bone formation.

The sphenoid bone ossifies with the intramembranous and endochondral ossification process which give rise to the basisphenoids (body), orbitosphenoids (lesser wings) and alisphenoids (greater wings). In lower mammals a space is seen between the alisphenoid, the basisphenoid, and the periotic capsule or petrous bone which is known as the primitive foramen lacerum medius. Shapiro and Robinson, 1967 found that in lower mammals, the mandibular nerve is sunken in the foramen lacerum medius. Wood Jones, (1931) further explained that as the mandibular nerve sinks into the greater wing of the sphenoid bone between the internal carotid and stapedial arteries, gradually a groove, then a notch, and ultimately a true foramen develops. This transitional development of the foramen ovale is demonstrable in lower mammals and may explain some of the variants of this foramen observed in humans [Lawrence et al 1994]. Thus, in humans, the foramen ovale develops from primitive foramen lacerum medius and the space persists as the foramen lacerum after formation of the carotid canal medially and the sphenopetrosal fissure posterolaterally. Foramen ovale is seen as a discrete foramen at 22 weeks. The perfect ring-shaped formation of the foramen ovale has been reported in the 7th fetal month, as earliest and at 3 years after birth, the latest (Yanagi, 1987).

In the present study the Foramen ovale was present in all 50 skulls on both sides. Out of 100 foramen studied , the shape of the foramen ovale was oval in 66 cases while Almond shaped in $22 \%$, D shaped in $2 \%$ longitudinal slit like in $4 \%$ cases, round in 3\% and irregular in 3\% cases. Yanagi, 1987, Ray et al (2005), Sharma and Garud (2011) have also reported variation in shape and size of Foramen ovale. They reported Oval and Almond shape were the most typical for the foramen, less frequently, round and longitudinal. Wadhwa et al (2012) in their study on 60 foramen found oval in $42(70 \%)$, round in $6(10 \%)$ and almond shaped in $10(15 \%)$ cases and longitudinal in $3(\%)$. Patel and Mehta (2014) in their study on 200 foramen found oval shaped in $119(59.5 \%)$, round in $55(27.5 \%)$ and Almond in 24 $(12 \%)$ cases and slit like in 2 (\%). John and Thenmozhi (2015) reported $48(60 \%)$ oval, $4(6 \%)$ round, $7(11.6 \%)$ almond shaped and 1 longitudinal / slit like foramen ovale out of 60 studied. D shaped foramen as reported by us was also reported by Diami et al(2011) reported oval in $29.87 \%$, D shaped $46.16 \%$, Round $12.52 \%$, Slit like $1.04 \%$, but the incidence reported by them is much higher than us, moreover almond shaped FO was not found by them. The difference could be because of the ethnic variations.

Lindblom (1936), Henderson (1966) explained that the venous asymmetry of emissary vein, connecting Cavernous Venous sinus \& Pterygoid Venous plexus probably accounts for asymmetry in the size and shape of the foramina ovale throughout the natural life. 
It is worth mentioning that bilaterally symmetrical foramen ovale were observed in only 30 skulls with bilateral oval in 24, bilateral almond shaped in 4 , and bilateral longitudinal in 2 skulls. Similar bilateral symmetry was reported by Sharma and Garud (2011) and Ray et al. (2005), as bilateral oval in only 15 cases, while bilateral almond-shaped foramen were seen in 7 cases out of 35 skull. In rest of the skull shapes were asymmetric on right and left. Asymmetry between the right and the left side was observed by Burden et al (2011), Lawrence et al (1994).

The outline of some foramen was associated with accessory bony structure viz. a bony plate was present in $8 \%$ cases, spine in $7 \%$ cases, septa in $2 \%$, tubercle in $5 \%$. However no bony accessory structure was seen in $47 \%$ cases. A thin bony septa perpendicular to the long (i.e. medio-lateral) axis of the foramen observed in 2 foramen dividing the foramen into two compartments of approximately equal size. (Fig.9).

Similar accessory bony structure were also reported in past. Wadhwa et al. in 60 foramen found bony plate in 6 , spine in 1 and tubercle in 2 cases. John and Thenmozhi (2015) found bony plate in 7, spine in 8 tubercle in 4 cases in their study on 60 foramen. A study on Polish population by Burden (2011) found in 24.2\% of cases, the occurrence of bony plates $(4 \mathrm{R}, 5 \mathrm{~L})$, spines $(1 \mathrm{R}, 2 \mathrm{~L})$, and marginal tubercles $(1 \mathrm{R}, 2 \mathrm{~L})$ as well as spurs $(1 \mathrm{R}, 1 \mathrm{~L})$ which completely divided the foramen into two asymmetrical parts, in general. Ray et al (2005) also reported two oval foramina divided into two compartments by a bridge like bony spur.

Ray et al (2005), Khan et al (2012) claimed that the various bony structure indicate bony overgrowth during its developmental process between its first appearance and perfect ring formation.

The emissary vein is separated from other structures by dense connective tissue which may occasionally be ossified resulting in the duplication of the foramen ovale. Tubbs et al. (2009), Reymond et al. (2005) Osunwoke et al. (2005) also reported a bony spur partially dividing the foramen ovale into 2 compartments. In such cases the partitioning of the foramen ovale could have resulted in the compression of the mandibular nerve with the subsequent neuralgia over the mandibular and preauricular region of the face, along with the motor signs such as paresis of the muscles developing from the mesoderm of the first branchial arch (Sharma and Garud, 2011). However, in the absence of relevant clinical histories, such correlations could not be confirmed in the present study. Such bony obstructions could also interfere with transcutaneous needle placement into the foramen ovale. These anatomical variations in the form of accessory bony structures on the borders of the foramen ovale in some skulls may also mistakenly suggest the presence of morbid changes on radiographs.

In the study, the mean length and mean width of foramen ovale in male skulls was $7.50+/-0.90 \mathrm{~mm}$ and $4.20+/-0.70$ $\mathrm{mm}$ and $7.7+/-1.00 \mathrm{~mm}$ and $3.9+/-0.80 \mathrm{~mm}$ in the female skulls. The range of length of foramen ovale in males was 5.4$10.2 \mathrm{~mm}$ while it was $5.4-11.1 \mathrm{~mm}$ in females. The overall range of length of foramen ovale irrespective of sex was 5.4$11.1 \mathrm{~mm}$ and the range of width was $1.7-8.2 \mathrm{~mm}$. There was no significant difference between right and left sides on both sexes. However there was highly significant statistical difference between the two sexes. (Table 3 and 4 ).

The results are much in consonance with previous studies. In a study by Ray et al (2005) the average length and width on the right side was $7.46 \pm 1.41 \mathrm{~mm}$ and $3.21 \pm 1.02 \mathrm{~mm}$, respectively, whereas on the left side it was $7.01 \pm$ $1.41 \mathrm{~mm}$ and $3.29 \pm 0.85 \mathrm{~mm}$, respectively. Berlis et al(1992), Calcaterra et al (1973). Lindblom K (1936) Schelling 1978, Yanagi (1987), Patel and Mehta et al (2014), Lang et al (1984)have reported the length varying in the range from 6.5 to $11.3 \mathrm{~mm}$ and width from 3.6 to $4.7 \mathrm{~mm}$. They too did not observe any significant difference between right and left side in length and width $(\mathrm{p}>0.05)$.

In our study mean length and mean width were similar to past authors. However the upper limit of range of width was much higher as $8.2 \mathrm{~mm}$ which can be explained because of the inclusion of the wide primitive foramen (fig. 5A) in the measurements.

The length and width of the foramen ovale was insignificantly higher in males than in females in a study conducted in Poland by Burden (2011). But in the present study the sexual dimorphism was highly significant.

An extremely primitive variant was seen in the study i.e. complete absence of the foramen ovale as a separate orifice is the persistent foramen lacerum medius ( fig 5 A) (Lawrence et al 1994) which is confluence of the foramen ovale and the foramen spinosum and absence of a medial bony separation from the foramen lacerum. A pithicoid type of foramen ovale (which is partially open to the foramen lacerum and is a frequent feature in apes) was seen in $16 \%$ of roentgenograms reviewed by Sondheimer (1971) and $4 \%$ of skulls bilaterally and $2 \%$ unilaterally in the study by Berge and Bergman (2001).

The foramen spinosum also develops in a similar manner as the foramen ovale, confluence of these two foramina is also a well-described occurence (Burden, 2011) but was seen only in two ( $2 \%$ ) cases in the present study (fig 5B-C). 
Surgical interventions on the infratemporal fossa require an accurate knowledge of the surgical anatomy. The foramen ovale is consistently the lowest point of the middle cranial fossa (Dayoub, 2010). For the study of topographic location of foramen ovale, its distance from two bony landmarks on zygomatic arch was measured viz. the anterior root of the zygomatic process and the articular tubercle on it. The knowledge of distance from these bony landmarks can be of help in the approach through transjugal-transoval route as described by Hartel in 1912, through the pterygomaxillary fossa up to the Foramen Ovale. In this approach, the anatomical region crossed by the biopsy needle is an inverted, three-sided, pyramid, with its apex as a cutaneous point, $3 \mathrm{~cm}$ lateral to the labial commissure on cheek. Its triangular base, located at skull base, is delineated by the three landmarks viz. a) the supero-lateral one is a cutaneous point on the orbito-meatal line along the inferior border of the zygoma, $3 \mathrm{~cm}$ anterior to the tragus b)the superomedial one corresponds to the papilla and c) the deep-seated one is the Foramen Ovale (FO) itself (Sindou et al 2012).At the base of the pyramid i.e. at the skull base, the vital structures the internal jugular vein, internal carotid artery, membranous part of auditory tube and even optic nerve are at high risk of injury so the surgical caution is a must.

In the present study the mean distance of foramen ovale from articular tubercle on zygomatic arch was $32.8+/-2.8$ $\mathrm{mm}$ in males and $31.1+/-2.4 \mathrm{~mm}$ in females. Lang 1984 reported that the mean distance from the upper edge of the zygomatic Process above the articular tubercle to the lateral rim of the Foramen ovale increases from about $15 \mathrm{~mm}$ in new born to $34.33 \mathrm{~mm}$ in adult. In a study, the average distance of the foramen ovale from the zygoma was reported as $38.2 \mathrm{~mm}$. (Tiwari, 1998).

In the present study the mean distance from anterior root of Zygomatic arch was 21.4 +/- $1.9 \mathrm{~mm}$ in males and 21.6 +/- $1.7 \mathrm{~mm}$ in females. Dayoub 2010, reported the distance between the temporalis muscle to lowest point of mid cranial fossa (floor) measurement (muscle thickness + mid-zygoma-to-floor measurement) as $24.16+/-0.74 \mathrm{~mm}$. The mean distance between Meckel's Cave and the medial surface of the posterior root of the zygomatic arch was 26.5 $\mathrm{mm}$. Meckel's Cave is best identified medial to the Foramen Spinosum and just posterior to the Foramen Ovale. The distance between the Trigeminal Ganglion and the Foramen Ovale ranges from 0 to $10 \mathrm{~mm}$ (Henderson 19660). Not many specific references for the distance of foramen ovale and articular tubercle and anterior root of zygomatic arch could be found in literature. So our study for these dimensions can be of much help to neurosurgeons.

\section{CONCLUSION}

The shape of foramen ovale was variable, typically oval in most of the skulls (66\%) followed by almond shaped. Accessory bony structure was seen like bony plate sides, spine and bridge like bony septa dividing the foramen. There was no significant difference in measurements of various metric parameters between right and left sides of foramen ovale $(p>0.05)$ but highly significant difference was observed between male and female dimensions of all metric parameters. $(\mathrm{p}<0.001)$. The foramen ovale does not exhibit bilateral symmetry but sexual dimorphism is evident. The data is helpful for surgical practices.

\section{REFERENCES}

Berge JK, Bergman RA (2001) Variations in size and in symmetry of foramina of the human skull. Clin Anat, 14: 406-413.

Berlis A, Putz R, Schumacher M (1992) Direct and CT measurements of canals and foramina of the skull base. Br J Radiol, 65: 653-661.

Burdan, W. Umławska, W. Dworzański, R. Klepacz, J. Szumiło, E. Starosławska, A. (2011) Drop Anatomical variances and dimensions of the superior orbital fissure and foramen ovale in adults Folia Morphol. Vol. 70(4): 263-271

Calcaterra TC, Cherney EF, Hanafee WF (1973) Normal variations in size and neoplastic changes of skull foramina. Laryngoscope, 83: 1385-1397.

Daimi SR, Siddiqui AU, Gill SS (2011) Analysis of foramen ovale with special emphasis on pterygoalar bar and pterygoalar foramen Folia Morphol. Vol. 70(3): 149-153

Dayoub H, Schueler WB, Shakir H, Kimmell KT, Sincoff EH (2010) The relationship between the zygomatic arch and the floor of the middle cranial fossa: a radiographic study. Neurosurgery, 66(6 ) : 363-369.

Edinger T, Kitts DB (1954) The foramen ovale. Evolution 8: 389-404.

Hauser G, DE Stefano GF (1989) Epigenetic variant of the human skull. Schweizebart, Stuttgart.

Henderson WR. (1966) A note on the relationship of the human maxillary nerve to the cavernous sinus and to an emissary sinus passing through the foramen ovale. J Anat;100: 905-908

John D A, Thenmozhi (2015) Anatomical Variations of Foramen ovale J. Pharm. Sci. \& Res. Vol. 7(6), 2015, 327-329

Kato H, Kanematsu M, Goshima S, Kondo H, Nishibori H, Tsuge Y, Yokoyama R, Hoshi H, Shiratori Y, Onozuka M (2006) Skull base metastasis from hepatocellular carcinoma revealed by cranial nerve palsy: Reports of two cases. Eur J Radiol, 54: 1-4.

Khan AA, Asari MA, Hassan A (2012) Anatomic variants of foramen ovale and spinosum in human skulls. Int. J. Morphol., 30(2):445-449. 
Lang J, Maier R, Schafhauser O (1984). Postnatal enlargement of the foramina rotundum ovale at spinosum and their topographical changes. Anatomischer Anzeiger 156(5): 351-387.

Lawrence EG, Steven WP, Michael YM C, Allen DE (1994) Skull-Base Foramina of the Middle Cranial Fossa: Reassessment of Normal Variation with High-Resolution CT Am J Neuroradio,15:283-291

Lindblom K (1936) A roentgenographic study of the vascular channels of the skull. Acta Radiol, 30: 211- 223.

Lindblom K. (1936) A roentgenographic study of the vascular channels of the skull, with special reference to intracranial tumors and arterio- venous aneurysms. Acta Radio, 30:1-146

M. Sindou, M. Messerer, J. Alvernia, and G. Saint-Pierre Percutaneous biopsy through the foramen ovale for parasellar lesions: surgical anatomy, method, and indications Advances and technical standards in neurosurgery 2012, XIV, 190

Osunwoke E.A, Mbadugha C.C, Orish C.N, Oghenemavwe E.L. and Ukah C.J (2005)A morphometric study of foramen ovale and foramen spinosum of the human sphenoid bone in the southern Nigerian population Journal of Applied Biosciences 26: 1631 - 1635

Patel R, Mehta CD (2014) Morphometry of Foramen Ovale at base of skull in Gujarat IOSR Journal of Dental and Medical Sciences Volume 13 (6) (IV) : 26-30

Ray B, Gupta N and Ghose S (2005). Anatomic variations of foramen ovale. Kathmandu University Medical Journal, 3: 64-68.

Reymond J, Charuta A, Wysocki J (2005) The morphology and morphometry of the foramina of the greater wing of the human sphenoid bone. Folia Morphol, 64: 188-193.

Schelling F (1978) The emissaries of the human skull. Anat Anz, 143: 340-382.

Shapiro R, Robinson F. (1967) The foramina of the middle fossa: a phylogenetic, anatomic and pathologic study. AJR Am J Roentgenol 1967; $101: 779-794$

Sharma NA., Garud R S (2011) Morphometric evaluation and a report on the aberrations of the foramina in the intermediate region of the human cranial base: A study of an Indian population Eur J Anat, 15 (3): 140-149

Sondheimer FK. (1971) Basal foramina and canals. In: Newton TH, Potts DG, eds. Radiology of the skull and brain: the skull. Vol 1, Book 1. St. Louis: Mosby, 1971:287-347

Tiwari R (1998) Surgical landmarks of the infratemporal fossa. Craniomaxillofac surg. Apr; 26 (20): 84-6

Tubbs RS, May WR, Apaydin N, Shoja MM, Shokouhi G, Loukas M, Cohen Gadol AA (2009) Ossification of ligaments near the foramen ovale: an anatomic study with potential clinical significance regarding transcutaneous approaches to the skull base Neurosurgery, 2009 (65) (6): 60- 64

Wadhwa A, Sharma M, Kaur P (2012) Anatomic variations of foramen ovale- clinical implications International Journal of Basic and Applied Medical Sciences, Vol. 2 (3) : 21-24

Wood-Jones F. (1931) The non-metrical morphological characters of the skull as criteria for racial diagnosis. Part 1: general discussion of the morphological characters employed in racial diagnosis. J Anat 1931; 65:179-195

Yanagi S (1987). Developmental studies on the foramen rotundum, foramen ovale and foramen spinosum of the human sphenoid bone. The Hokkaido journal of medical science 62(3) 485-496 
MJMBR listed in CSE member's journals database

http://www.councilscienceeditors.org/about/members-journals/

Indexed in Google Scholar

https://scholar.google.com/citations?hl=en\&user=JH23W_8AAAAJ

MJMBR Following the ICMJE Recommendations (list date 7/1/14)

http://www.icmje.org/recommendations/

RoMEO: This is a RoMEO blue journal

http:/ / www.sherpa.ac.uk/romeo/search.php?issn=2313-0008

Author's Pre-print: author cannot archive pre-print (ie pre-refereeing)

Author's Post-print: author cannot archive post-print (ie final draft post-refereeing)

Publisher's Version/PDF: author can archive publisher's version/PDF

\section{(c) (1) ()}

This journal is licensed under a Creative Commons Attribution-NonCommercial 4.0 International License. Articles can be read and shared for noncommercial purposes under the following conditions:

- $\quad B Y:$ Attribution must be given to the original source (Attribution)

- NC: Works may not be used for commercial purposes (Noncommercial)

This license lets others remix, tweak, and build upon your work non-commercially, and although their new works must also acknowledge you and be non-commercial, they don't have to license their derivative works on the same terms.

License Deed Link: $\underline{\text { http://creativecommons.org/licenses/by-nc/4.0/ }}$

Legal Code Link: http://creativecommons.org/licenses/by-nc/4.0/legalcode

MJMBR uses the CC BY-NC to protect the author's work from misuse. 